\title{
SOBRE PROFESSORES, COLABORAÇÃO E TECNOLOGIAS: \\ REFLEXÕES SOBRE OS PROCESSOS COLABORATIVOS E O USO DA TECNOLOGIA NA EDUCAÇÃO
}

\section{Daniela Karine Ramos}

\section{RESUMO}

A colaboração é uma ação social, na qual pessoas compartilham objetivos e aprendem juntas, visando superar desafios e construir conhecimentos. Nesta ação, destacamos o suporte das tecnologias da informação e da comunicação para o desenvolvimento deste tipo de atividade, independentemente de tempo e espaço, oferecendo vantagens para organização, compartilhamento, registro de informações e oferta de ferramentas para a comunicação e construção de textos coletivos. A partir destes pontos, investigamos o uso de tecnologias consideradas colaborativas em ambientes escolares. Neste trabalho, analisamos as relações e as compreensões dos professores sobre a colaboração e o uso de tecnologias na educação. A partir da pesquisa realizada numa escola pública de Ensino Fundamental de Florianópolis, em Santa Catarina, abrangendo a proposta de atividades com aos alunos e a coleta de dados, apresentamos os resultados relacionados à compreensão e ao uso da colaboração como estratégia pedagógica e da tecnologia, principalmente a Internet.

\section{PALAVRAS-CHAVE}

Colaboração; Tecnologia; Formação de professores

\section{ABOUT TEACHERS, COLLABORATION AND TECHNOLOGIES: REFLECTIONS ON COLLABORATIVES PROCESSES AND USE OF TECHNOLOGY IN EDUCATION}

\begin{abstract}
Collaboration is a social activity in which people share objectives and learn together to overcome challenges and build knowledge. In this action we detach the support of information and communication technologies in the development of this type of activity, independent of time and space, offering advantages to the organization, sharing and registering of information and the provision of tools for the communication and construction of collective texts. Based on these factors, we investigated the use of technologies considered collaboratives in school environments. In this work we analyze the teacher relations and understandings about the collaboration and the use of technologies in the education. Through a research carried in a public school located in the city of Florianópolis, Santa Catarina, involving the proposal of activities with the students and the collects of data, we present the results related with the understanding and the use of the collaboration as pedagogical strategy and the technology, mainly the Internet.
\end{abstract}

\section{KEYWORDS}

Collaboration; Technologie; Formation of teachers 
A inserção das tecnologias na sociedade e na educação suscita reflexões, estudos, práticas, metodologias, políticas públicas e investimento para utilização deste suporte visando agregar qualidade e possibilidade de inclusão digital. Diante disso, abordamos a colaboração como estratégia pedagógica para utilização da Internet como suporte tecnológico e discutimos a formação de professores para atuar neste contexto educacional.

Entendemos a colaboração como uma ação social, na qual as pessoas se juntam com o objetivo atingir metas em comum e superar desafios. A fim de ilustrar esse entendimento, chamamos a atenção para a forma de organização dos gansos quando em vôo, visto revelar um verdadeiro sistema colaborativo. Os gansos voam em $V$, pois, ao bater as asas, a ave que esta à frente cria sustentação para a ave seguinte, e assim sucessivamente, o que exige menos esforço. No entanto, para que isto ocorra é preciso que todas estejam indo para a mesma direção.

Além disso, um ponto a destacar nessa formação é a necessidade de revezamento da ave que está no vértice do $V$, à frente de todas as outras, conduzindo e indicando a direção. Essa ave é a mais exigida durante o vôo, pois não há outra à sua frente; logo, não recebe apoio para a sua própria sustentação. O desenho da formação dos gansos - vôo em grupo, com revezamento - revela uma interessante estratégia posta em prática para enfrentar os desafios e tornar menos árdua a trajetória a ser percorrida.

A forma de organização dos gansos nos propicia criar uma metáfora aplicável à organização de grupos humanos em atividades colaborativas, pois, para colaborar, é preciso compartilhar objetivos e ter metas comuns. Isto significa que é necessário flexibilizar os papéis nos grupos e enfatizar que nenhum integrante deve ser prejudicado. Esses princípios, aplicados aos processos educativos, contribuem para a aprendizagem de todos os integrantes do grupo. Destacamos, então, que a citada ilustração encerra alguns elementos importantes da atividade colaborativa.

\section{POSSIBILIDADES DE TRABALHO COLABORATIVO MEDIADO PELA TECNOLOGIA}

As reflexões e conceitos abordados neste artigo resultam de um trabalho de pesquisa, realizado em uma escola pública de Florianópolis. Propusemos, nessa escola, a realização de uma atividade criada com fundamento na perspectiva da Metodologia da Problematização e da proposta da WebQuest, a qual foi publicada num ambiente virtual de aprendizagem. A 
atividade foi desenvolvida em duas turmas de oitava série, na disciplina de História, e o tema abordado foi "Primeira e Segunda Guerra Mundial”.

A partir desta atividade, investigamos o conceito de colaboração na organização do cotidiano escolar, a utilização dos recursos tecnológicos - principalmente a Internet, o trabalho colaborativo com base em desafios, tanto da perspectiva dos alunos como dos professores. Neste artigo nos concentramos na perspectiva dos professores.

A idéia de investigar os processos colaborativos utilizando a Internet como meio, com base na proposta de desafios, surge do questionamento sobre a efetividade do potencial desse tipo de atividade. Assim, o objetivo é analisar as possibilidades e os limites da aprendizagem colaborativa apoiada por computador no processo educacional.

A utilização do computador tende a oferecer vantagens e possibilidades à educação, o que está intrinsecamente relacionado ao modo como é utilizado, ou seja, o computador não é a solução para os problemas educacionais, mas configura-se como um meio para iniciativas e propostas para tal fim. Neste sentido, a utilização criativa do computador é que permite avançar e promover a construção de conhecimentos.

Ressaltamos, entretanto, que para a utilização dessa tecnologia, o planejamento e o estabelecimento de estratégias pedagógicas para promover o aprendizado colaborativo suportado pela internet são muito importantes. Neste sentido, destacamos o papel desempenhado pelo professor.

Segundo Campos et al (2003), este desafio inicia-se por um problema, o qual deve ser voltado para a realidade, o que, por sua vez, exige uma contextualização. O ponto de partida de um problema visa fazer com que o aluno estude determinado conteúdo, estimulando a busca ativa por conhecimento (SAKAI; LIMA, 1996 apud BERBEL, 1998). Do mesmo modo que uma WebQuest parte de um desafio.

A idéia de problemas e desafios corrobora o entendimento de que "a inteligência é a função que só se ‘ativa' diante de uma situação-problema. Ora, todo processo escolar que não ‘desafia’ é frenagem ao desenvolvimento desta função” (LIMA, 1982, p.13). O que vem demonstrar a efetividade desta metodologia baseada na proposta de desafios para a construção do conhecimento e promoção de ações colaborativas.

A partir dessa proposta o aluno é exposto a situações desafiadoras, construídas por meio de problemas colocados para grupos de alunos. De maneira simples “o professor propõe um caso ou problema, para que alunos em grupo analisem-no, pesquisem, discutam, interpretem e produzam possíveis explicações ou soluções” (TEIXEIRA, 2002, p. 18). 
Tal tipo de proposta é indicado com ênfase para o desenvolvimento de trabalho em grupo, visando incentivar a colaboração. Esta relação é descrita por Piva (2002, p. 88), no entendimento da aprendizagem colaborativa "como grupos de alunos trabalhando de forma interativa para resolver problemas”.

A esse respeito, a sala de aula, como espaço social de aprendizagem, “deve ser organizada sob a forma de situações, nas quais os alunos enfrentam problemas a resolver (...); este contexto permite aos alunos realizar atividades coletivas, nas quais suas ações são coordenadas e instrumentos cognitivos são elaborados” (GARNIER et al, 1996, p. 215).

\section{SOBRE PROFESSORES: OS SUJEITOS DE NOSSA PESQUISA}

Quando pensamos na inserção de tecnologia na escola e na inclusão digital dos alunos a partir desse espaço, precisamos pensar na formação do professor para atuar nesse sentido. Assim, para conhecer um pouco quem eram os professores da escola pública na qual o trabalho de pesquisa foi realizado, aplicou-se um questionário.

Deram respostas ao questionário 23 professores que trabalham no Ensino Fundamental (de $1^{\mathrm{a}}$ a $8^{\mathrm{a}}$ série). Estes possuem em média 36,6 anos de idade, sendo que o professor mais novo tem 23 anos e o mais velho, 51. Trabalham como professores em média há 12,9 anos, sendo que o tempo de atuação no magistério desse público vai de 1 a 39 anos. Assim, é um grupo bem diversificado, com distanciamentos temporais bem grandes, tanto de idade como de tempo de atuação.

No que diz respeito ao domínio e ao uso da tecnologia, a maioria desses professores, cerca de 90,9\%, sabe utilizar o computador, e 95,45\% sabe navegar na Internet. Destacamos que é maior o número de professores que sabem navegar na rede, do que se depreende que não é necessário saber utilizar o computador para navegar na Internet.

Essa diferença encontrada nos dados revela que o uso do computador restringe-se ao acesso à rede, ou seja, não é utilizado para outra finalidade. Assim, o professor navega pela Internet, possivelmente, com o auxílio de outra pessoa ou dominando conhecimentos básicos para obter informações, fazer pesquisas, entre outras possibilidades, sem utilizar, por exemplo, um editor de texto.

No entanto, o número de professores que utilizam a Internet em sala de aula é inferior. Cerca de 68,18\% dos professores utiliza esse recurso como estratégia para promoção do aprendizado. 
Outro dado obtido por meio do questionário refere-se ao acesso ao computador e à rede. Mostra-se que há um percentual bastante expressivo de professores com acesso à rede no contexto em que a pesquisa foi realizada. Além disso, destacamos que o local ao qual os professores têm mais acesso é em casa, e o segundo local com maior acesso é a escola em que trabalham.

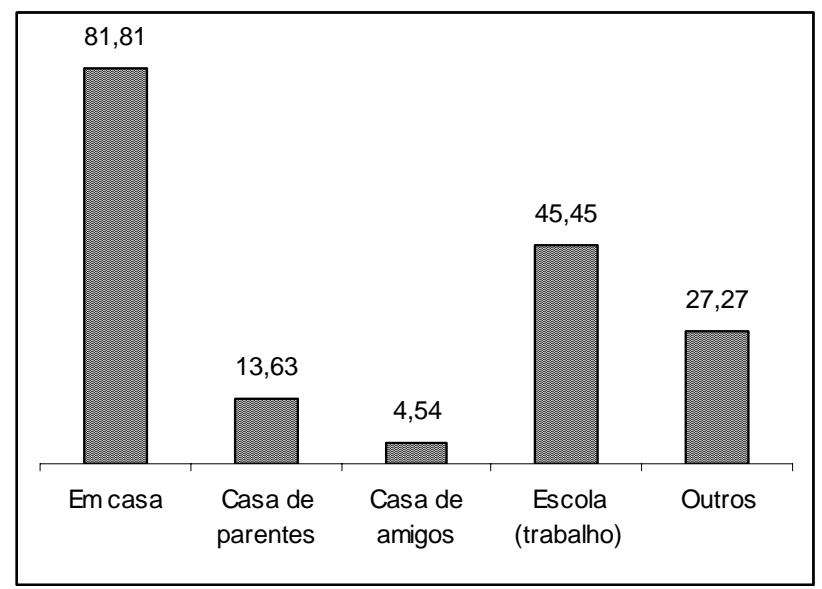

Gráfico 1 - Local de acesso dos professores ao computador

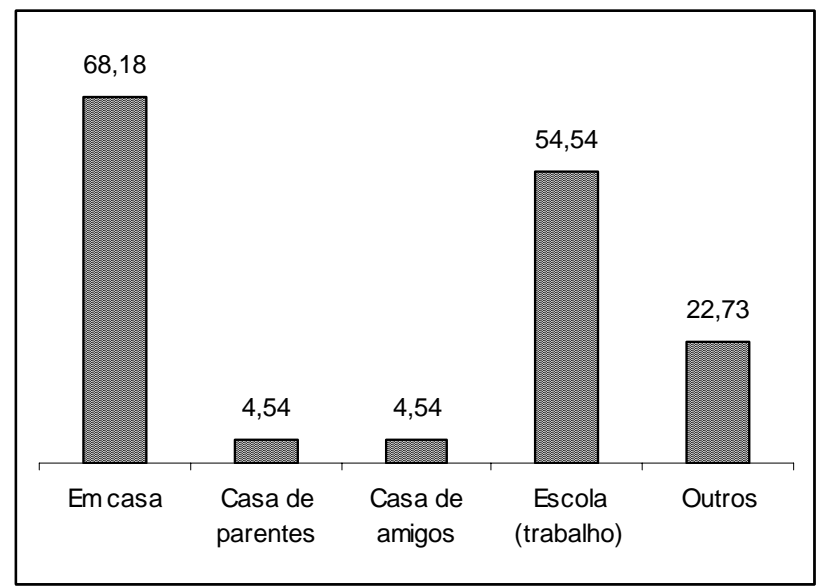

Gráfico 2 - Local de acesso dos professores à rede

Os dados obtidos apontam para uma realidade na qual o professor, em sua maioria, tem acesso ao computador em casa ou na escola em que trabalha, bem como tem algum domínio da tecnologia; no entanto, não há uma relação direta e proporcional ao uso do computador e da Internet como recurso pedagógico. O que nos leva à seguinte questão: por que tal professor não utiliza esse recurso? Podemos supor que ele não teve formação para o 
uso, não sabe como utilizar o recurso nas atividades pedagógicas, não se sente totalmente preparado, entre outras hipóteses.

Diante disso é que propomos e divulgamos a necessidade de uma metodologia, ou pelo menos uma possibilidade, para o trabalho com o computador ligado à rede e à ênfase na colaboração, não só entre os alunos, mas também entre professor e alunos, os quais podem aprender juntos e trocar conhecimentos sobre o uso da tecnologia.

\section{SOBRE A COLABORAÇÃO: O QUE OS PROFESSORES ENTENDEM E COMO TRABALHAM}

$O$ ato de ensinar pode ser feito de diversas maneiras, utilizando-se diferentes fundamentos teóricos, metodologias e recursos. Aproximando-se da forma mais tradicional de ensino, esta ocorre em três tempos: ouvir ou ler, pensar (o que pode ser um exercício de memorização) e executar. Isto consiste num processo linear e vertical (KENSKI, 2002).

O uso das tecnologias contribui para romper com a verticalização da relação entre o aprendiz e o mestre, e com a linearidade de acesso à informação, tendo em vista que "interagir com o conhecimento e com as pessoas para aprender é fundamental. Para transformação de um determinado grupo de informações em conhecimentos é preciso que estes sejam trabalhados, discutidos e comunicados” (KENSKI, 2002, p. 258).

Nessa perspectiva, a colaboração é uma possibilidade de se romper com a linearidade e favorecer a construção do conhecimento. Assim, propomos a discussão, principalmente, da colaboração apoiada pelo computador.

Referimo-nos à colaboração como atividade "coordenada que resulta de uma tentativa contínua de construir e manter uma concepção compartilhada de um problema” (ROSCHELLE; TEASLEY, 1993 apud ROSATELLI et al, 2003, p. 48) e como a ação de “atuar junto, de forma coordenada, no trabalho ou nas relações sociais para atingir metas comuns, sendo que as pessoas colaboram pelo prazer de repartir atividades ou para obter benefícios mútuos” (ARGYLE, 1991 apud CAMPOS et al, 2003, p. 25). Além disso, a colaboração caracteriza-se como uma ação na qual os objetivos e os problemas são partilhados (DILLENBOURG, 1996; ROSATELLI et al, 2003), visando à construção do conhecimento e a aprendizagem, tendo em vista que "a qualidade do aprendizado é maior quando há o envolvimento dos alunos na elaboração efetiva de um produto” (SANTORO et al, 2002, p. 358). 
Desse modo, observamos que as atividades colaborativas reestruturam as relações sociais e os papéis dos sujeitos no processo educativo, pois os alunos passam a ser responsáveis pela organização do trabalho, buscam fontes de pesquisas e têm o foco nas contribuições dos integrantes do grupo. O professor, por sua vez, passa a ser fundamental no planejamento da atividade e na concepção da proposta, pois durante o desenvolvimento da atividade orienta os alunos e os auxilia na resolução de suas dúvidas. Contudo, cabe ao grupo definir a sua trajetória.

A partir dessa dinâmica, o professor passa a ser o mediador no decorrer do desenvolvimento das atividades colaborativas. Em vez de fornecer as informações no modelo da aula expositiva, ele estrutura o ambiente colaborativo, visando incentivar a interação entre os alunos (CAMPOS et al, 2003). O professor pode auxiliar na busca das informações e préselecionar materiais que possam auxiliar os alunos no desenvolvimento da atividade colaborativa proposta. Além disso, acompanha e assessora o aluno no processo de construção do conhecimento, ao atuar como orientador e mediador nas interações estabelecidas entre os grupos de trabalho.

Paralelamente aos conceitos desses autores, buscamos os conceitos de colaboração existentes no interior da escola, observando a forma como aparecem no discurso e na ação dos professores. Por meio de questionário, procuramos identificar a compreensão dos professores quanto à colaboração. A seguir, organizamos e reproduzimos seus conceitos:

a) Colaboração como troca

Troca de conhecimento em outro canal onde pode ocorrer o processo de ensino aprendizagem (Professor $\mathrm{C})^{1}$.

Troca de experiência (Professor L).

Colaboração é a troca de experiências, a troca de observações (Professor O).

b) Colaboração como ajuda

Ajuda e participação (Professor B).

Ajuda mútua, professores ouvindo, alunos interessados, material disponível, momentos para conversar (Professor M).

Colaboração é uma forma de ajudar (Professor J).

c) Compartilhamento

\footnotetext{
${ }^{1}$ Os professores e professoras são identificados pela denominação Professor, seguida de uma letra. Destaca-se, ainda, que os números correspondem, nas diferentes citações, ao mesmo professor ou professora.
} 
Informar o que de melhor se obteve referente a determinada tarefa. Orientar as melhores saídas, as mais saudáveis atividades (Professor T).

Dispor o que tem que seja útil a alguém (Professor E).

O resgate das concepções teóricas sobre a colaboração possibilita a identificação de pontos de convergência com as opiniões dos professores, pois a troca, a ajuda mútua e o compartilhamento são processos necessários para a efetivação do trabalho colaborativo.

Alguns professores aproximam-se do conceito mais amplo de colaboração. Segundo o Professor L, a colaboração passa por um processo de construção coletiva por troca de experiências, por um planejamento articulado envolvendo todos os segmentos da escola. No entanto, há professores que confundem colaboração com o uso de tecnologias, como o Professor J, que descreve colaboração da seguinte forma: Seria o uso da Internet.

Apesar dos diferentes entendimentos sobre o que vem a ser colaboração, todos os professores afirmam utilizar estratégias colaborativas em sala de aula. Quando foi solicitado que o professor desse um exemplo dessas atividades, alguns descreveram as que seguem:
a) atividades de pesquisa;
b) confecção de painéis e mosaicos;
c) proposta de exercícios para discussão;
d) preparar e expor o conteúdo em equipe;
e) registro de freqüência;
f) organização da sala;
g) montagem e apresentação de teatro.

Algumas das atividades apontadas podem suscitar dúvidas, de acordo com o entendimento do que é colaboração, como, por exemplo, o registro de freqüência (Professor H), ao considerar que a participação e o envolvimento do aluno em algumas tarefas é um modo de colaboração. Neste mesmo sentido, o Professor V afirma a escolha de dois ajudantes por dia. Estas são atividades que auxiliam na responsabilização do aluno pelo espaço escolar, atuando como um monitor, o que se configura como forma de envolver o aluno de modo que ele se sinta responsável pela manutenção e preservação do ambiente escolar, e contribui para que o aluno se sinta útil, porém não é possível caracterizar a partir das concepções apresentadas como um trabalho colaborativo.

A colaboração como ajuda também se destaca nos exemplos das atividades colaborativas realizadas, como na opinião do Professor $\mathrm{M}$, ao falar da ajuda mútua nas 
atividades de sala de aula e na do Professor $\mathrm{R}$, ao se referir ao auxílio dos colegas que têm alguma dificuldade para realizar determinado exercício. Ajudar a socorrer colegas que sofrem algum machucado durante as aulas de educação física, como por exemplo, acompanhá-los até a sala de curativo.

Outra atividade relatada como exemplo de colaboração, pelo Professor T, é a sextafeira da cultura - são duas aulas onde os alunos apresentam poesia, música, teatro, dança, curiosidade. É um momento no qual deve haver respeito para quem está apresentando, interesse (para temas diversos) por parte dos alunos. Este é um momento de compartilhamento das produções dos alunos; no entanto, observa-se que não ocorre em conjunto, pois o professor não descreve se há discussão sobre o que é apresentado. Neste sentido, não seria possível classificar esta atividade como colaborativa, embora o compartilhamento seja um elemento importante da colaboração.

Apesar das diferentes concepções de colaboração, todos os professores reconhecem vantagens na utilização de estratégias colaborativas em sala de aula. A seguir, resumo as vantagens apontadas pelos professores e pelos autores pesquisados.

\begin{tabular}{|l|l|}
\hline \multicolumn{2}{|c|}{ Vantagens da colaboração } \\
\hline \multicolumn{1}{|c|}{ Para os professores } & \multicolumn{1}{|c|}{ Para os autores } \\
\hline $\begin{array}{l}\text { Possibilita a troca de experiências e } \\
\text { conhecimentos e viabiliza a } \\
\text { construçẫo coletiva do conhecimento. }\end{array}$ & $\begin{array}{l}\text { Possibilita a construçẫo do } \\
\text { conhecimento a partir do } \\
\text { compartilhamento dos problemas } \\
\text { (DILLENBoURG et al, 1996 e } \\
\text { RosATELI et al, 2003). }\end{array}$ \\
\hline $\begin{array}{l}\text { Desenvolve o espírito pesquisador e } \\
\text { amplia as fontes de informação que } \\
\text { nẫo se restringem aos materiais } \\
\text { didáticos, e incluem a discussẫo e } \\
\text { troca de idéias e experiências. }\end{array}$ & $\begin{array}{l}\text { Produçẫo de um conhecimento mais } \\
\text { profundo e um trabalho mais amplo e } \\
\text { completo (PALLOFF e PRAT, 2002 e } \\
\text { LUCENA, 1998). }\end{array}$ \\
\hline $\begin{array}{l}\text { Permite o desenvolvimento de } \\
\text { habilidades como de falar, de ouvir, } \\
\text { de organizaçẫo e de coerência. Além } \\
\text { disso, contribui com a integraçấo e } \\
\text { com a socializaçấo. }\end{array}$ & $\begin{array}{l}\text { Amplia as capacidades de interaçẫo } \\
\text { e comunicaçẫo social (CAMPOS et al, } \\
\text { 2003). }\end{array}$ \\
\hline $\begin{array}{l}\text { Compreende o exercício da } \\
\text { convivência, a divisẫo de tarefas e a } \\
\text { responsabilizaçẫo dos alunos pelo } \\
\text { trabalho. }\end{array}$ & $\begin{array}{l}\text { Desenvolve a responsabilidade dos } \\
\text { alunos e possibilita conhecer pontos } \\
\text { de vista diferentes (LABoRDE, 1996). }\end{array}$ \\
\hline
\end{tabular}

Quadro 1 - Vantagens da colaboração descritas por professores e autores. 
Essas vantagens são reforçadas nas observações dos professores, como a realizada pelo Professor Q, ao explicitar que percebe muitas vantagens, trabalho em equipe, socialização dos alunos e desenvolvimento do espírito pesquisador. Na pesquisa temos de fazer escolhas, de tomar decisões. No trabalho em equipe temos de defender nossa opinião baseada no que pesquisamos, sintetizamos e concluímos. Assim, tornam-se visíveis as questões sociais relacionadas ao trabalho colaborativo, tendo em vista que ocorre a relação social que possibilita, segundo Zanella (2001) e Laborde (1996), a confrontação de pontos de vista diferentes, ao promover a discussão e a negociação, o que por sua vez insere a possibilidade de aprimoramento das habilidades sociais que abrangem a comunicação, o respeito e a organização.

Além disso, o professor revela a necessidade de algumas condições para que o trabalho colaborativo seja proveitoso, como pode ser constatado na afirmação do Professor H: Até certo ponto, há sempre vantagens, há também problemas e podem ser maiores que o esperado. É bom quando a capacidade dos participantes sabe avaliar e respeitar os bons limites.

A partir das condições necessárias para o desenvolvimento de atividades colaborativas, ressalta-se que muitas vezes a falta de condições impõe dificuldades à sua realização, bem como ao preparo e disposição do professor para este tipo de atividade. Com relação às dificuldades para realização deste tipo de atividade, 63,16\% dos professores afirmam não as terem, 10,53\% afirmam que às vezes têm alguma dificuldade, e 26,32\% afirmam tê-las. Dentre as dificuldades apontadas pelos professores, descrevemos algumas:

a) desorganização do ambiente;

b) aumento da bagunça;

c) exige maior preparo;

d) necessita de criatividade.

A necessidade de preparo é aquela referente à atualização do professor para fomentar a discussão entre os alunos e contribuir com novos elementos para o trabalho, conforme diz o Professor M: Preciso aumentar meu repertório, pesquisar mais. Além disso, outra dificuldade apontada pelo Professor E refere-se ao fato de que, devido à idade, há muita bagunça, muito barulho. Isto chama a atenção, pois indica a necessidade e cobrança presente entre os professores sobre o domínio sobre a turma e evidencia resquícios de práticas características do ensino tradicional. 
Nesse sentido, destaca-se a necessidade de o professor ter uma atitude condizente com este tipo de proposta, como a abertura para aprender com os alunos, responsabilizá-los por sua aprendizagem, a criação de espaços para os alunos exporem suas idéias e entendimentos, e uma proposta conjunta de construção do conhecimento.

Essa atitude, por sua vez, exige maior empenho e preparo do professor, pois, segundo Campos et al (2003) e Andrade e Beiler (1999), o professor precisa estruturar o ambiente colaborativo por meio da definição de estratégias metodológicas, levantamento de informações, planejamento e acompanhamento da atividade, a fim de orientar a discussão, mobilizar e encorajar o diálogo. Além disso, ressaltamos que numa atividade colaborativa, principalmente mediada pela Internet, torna-se mais difícil o improviso, comum no cotidiano de trabalho do professor.

\section{SOBRE TECNOLOGIAS: COMO OS PROFESSORES AS UTILIZAM}

Neste trabalho focalizamos a colaboração on-line, que agrega novos elementos, mas não altera o conceito de colaboração. Esta ação passa a ser mediada pela rede eletrônica.

No que diz respeito às características e possibilidades oferecidas pelo uso do computador e da Internet em atividade colaborativas, Jollivet (2003) destaca que as NTICs, principalmente o computador ligado à rede, produzem máquinas tanto cognitivas quanto relacionais. A primeira característica refere-se ao potencial das NTICs na produção, circulação e capitalização de conhecimentos e, ainda, na comunicação como forma de transferência de informação. A segunda característica diz respeito ao entendimento destas tecnologias como instrumentos que permitem o relacionamento entre pessoas e a criação de relações inter-pessoais, bem como a formação de comunidades virtuais.

Atualmente, a utilização das tecnologias da informação e da comunicação oferece suporte para a formação de coletivos virtuais que não ocupam apenas um espaço determinado, mas se formam por integrantes conectados nas pontas da rede. Estes coletivos são denominados de comunidades virtuais. O que redimensiona o conceito de comunidade, pois altera as relações no tempo e no espaço. Neste sentido, Ferreira (2004, p. 99) afirma que as “comunidades virtuais são constituídas por grupos que possuem afinidades de interesses, projetos comuns, construção de conhecimentos coletivos por meio de trocas interativas e cooperação".

Assim, a utilização da Internet permite o acesso a novas possibilidades de comunicação, tanto síncronas como assíncronas, e a uma grande quantidade de informações. 
Esta possibilidade exige uma postura ativa do indivíduo para buscar, selecionar e transformar as informações e para relacionar-se com outras pessoas por meio da Internet.

A comunicação mediada pelos recursos da rede modifica o contexto das interações sociais, pois permite aos usuários a independência do tempo e do espaço, o que coloca novos elementos na ação comunicativa desvinculados do contato face a face.

Nesta gama de possibilidades, trabalhamos com a colaboração com a finalidade de agregar maior qualidade à atividade mediada pelo computador, proposta na escola pesquisada. Sendo assim, a Internet permitiu concretizar a colaboração entre os alunos para a solução dos desafios relacionados à disciplina de História, servindo como fonte de pesquisa e como meio de comunicação tendo em vista que os grupos formados eram compostos por alunos de diferentes turmas e de turno diferentes.

Nesse sentido, identificamos que o uso do computador oferece uma série de vantagens para a organização do processo educativo e possibilita a criação de um ambiente virtual, que oferece a possibilidade de colaboração a distância. Sendo assim, torna-se necessário avaliar as potencialidades do ambiente, no qual se propõe o desenvolvimento de uma atividade colaborativa, pois exerce grande influência sobre o trabalho realizado nesse espaço. No que diz respeito ao ambiente, vale destacar: o ambiente físico, a sala de aula ou um laboratório; e o virtual, tornado possível pelos recursos interativos da Internet.

Os ambientes virtuais possibilitam a criação de comunidades virtuais, principalmente, pela oferta de recursos de comunicação síncronos e assíncronos que possibilitam o estabelecimento de redes de debates (MAIA, 2000). Há também os ambientes virtuais de colaboração que podem ser definidos a partir da existência de um espaço virtual que, segundo Trefftz é “um mundo não material que permite interacção a distância para múltiplos utilizadores através de computadores ligados em rede” (TREFFTZ, 1996 apud GOUVEIA, 2000, p.3)e a formação de comunidades virtuais.

Segundo Mason (1998), o desenvolvimento tecnológico tem ampliado as possibilidades de comunicação, tanto a realizada em tempo-real, síncrona, como aquela realizada virtualmente, de forma assíncrona, estabelecida tanto de um indivíduo para outro, como de um para muitos ou entre muitos indivíduos. Essas formas de comunicação possibilitam a formação de grupos de trabalho colaborativo, e podem ser utilizadas como recursos tanto na educação a distância como no suporte ao ensino presencial.

Neste trabalho foi utilizado um ambiente virtual como apoio ao desenvolvimento da atividade colaborativa, para viabilizar a interação assíncrona dos alunos pesquisados. Esse 
ambiente possibilitou o gerenciamento dos trabalhos colaborativos, a formação de grupos, a publicação de materiais, a avaliação e acompanhamento pelo professor. Além disso, ofereceu ferramentas de comunicação síncrona e assíncrona.

Além disso, destacamos que o professor tem papel fundamental na difusão do uso das tecnologias nas escolas, pois ele é o responsável pelo planejamento e seleção dos recursos a serem utilizados. Ele pode direcionar o modo como a tecnologia é utilizada, o que se relaciona com a sua proposta de atividades. Diante disso, investigamos o uso que o professor faz da tecnologia e o modo como a colaboração é entendida e materializada em sala de aula.

Dentre os professores que participaram da pesquisa, 73,91\% utilizam a Internet para desenvolver atividades com os alunos, e 26,09\% não o fazem. A seguir, listo as atividades relatadas pelos professores:

a) procura de sites com assuntos relacionados ao tema da aula;

b) pesquisa em sites sugeridos pelo livro didático adotado;

c) pesquisa de um tema proposto pelo professor;

d) busca por sugestões de atividades disponíveis;

e) utilização de jogos educativos disponíveis na rede.

A atividade que mais se destacou entre os professores abrange a pesquisa, como relata o Professor T, que utilizou a Internet para realizar uma pesquisa sobre baleias, procurando em sites afins e apresentando para a turma o que pesquisou e onde pesquisou. O que demonstra o aproveitamento do potencial de divulgação de informações da rede e a aplicação desta contribuição à atividade corriqueira de ensino e aprendizagem. Ressaltamos, no entanto, outras possibilidades oferecidas pela Internet, principalmente as relacionadas à comunicação. As atividades que utilizam estas tecnologias podem enriquecer os processos de ensino e aprendizagem, bem como oferecem suporte para atividades colaborativas ao envolver pessoas de diferentes locais, o que tende a favorecer as trocas de informações e o contato com visões mais diversificadas sobre uma mesma problemática.

Apesar do uso limitado da Internet na escola, os professores apontam algumas vantagens relacionadas a isto. Eis as vantagens, segundo os professores:

a) possibilita trabalhar com informações atualizadas;

b) amplia as fronteiras da sala de aula;

c) permite o contato dos alunos com a Internet;

d) fonte de pesquisa;

e) cria um ambiente mais estimulante. 
Os professores identificam importantes vantagens no uso da Internet na escola, sendo que o destaque maior é atribuído à sua importância como fonte de pesquisa, visível por meio de afirmações como estas: A Internet é uma janela para as informações do mundo (Professor F); e [...] acrescenta, de maneira atualizada, os assuntos vistos em sala de aula (Professor A). Da mesma forma, a Internet configura-se como uma fonte atualizada de pesquisa devido à quantidade de informações colocadas à disposição, diariamente, e à facilidade de inclusão e divulgação de novos dados. A Internet permite, ainda, ultrapassar as barreiras físicas a partir da sua possibilidade de estabelecer contato com pessoas de diferentes locais, além de ser um espaço em que se pode obter informações e visualizar imagens de lugares geograficamente distantes. Segundo o Professor C, a Internet é um instrumento que abre portas para o mundo.

No entanto, a diversidade e a quantidade de informações disponíveis exigem que o aluno tenha a capacidade de pesquisar e selecionar essas informações. Pois a Internet oferece muitos atrativos, que podem dispersar o aluno dos objetivos educativos, como analisa o Professor L: A Internet é uma fonte rica de informações, porém precisamos cuidar e observar a qualidade delas, analisar, refletir e selecionar.

Juntamente com as vantagens, os professores apontam as dificuldades decorrentes da utilização da Internet nas atividades de ensino e aprendizagem. Para 47,83\% dos professores, a utilização da Internet representa algum tipo de dificuldade, enquanto que 30,43\% afirmaram não ter nenhuma dificuldade e 21,74\% dos professores não responderam a essa pergunta.

As dificuldades apontadas pelos professores podem ser sintetizadas a partir dos seguintes pontos:

a) falta de conhecimento técnico sobre o uso;

b) infra-estrutura insuficiente;

c) escassez de material em algumas áreas do conhecimento, direcionado para faixas etárias específicas;

d) dispersão dos alunos;

e) tamanho das turmas;

f) necessidade de planejamento prévio.

As dificuldades relacionadas à infra-estrutura são aquelas que dizem respeito à falta de computadores para todos os alunos, e têm uma relação direta com a dificuldade relacionada ao excessivo número de alunos em cada turma. No entanto, é possível realizar o trabalho no computador em duplas, o que permite a troca de experiências e a ajuda mútua no seu manuseio, aspecto que tem sido explorado no laboratório de informática. Alguns professores 
fazem acordos e negociações com os alunos, e procuram envolvê-los na atividade ou mesmo a organizam como forma de manter a disciplina.

Outro ponto importante é a necessidade de planejamento, ou seja, é preciso orientar os alunos, elaborar roteiros, propor sites de pesquisa e criar situações desafiantes e envolventes para que o uso da Internet possa ser construtivo e deflagrador de processos de aprendizagem. Neste sentido, destaca-se o que diz o professor U, para quem a única dificuldade é o tempo de preparo das aulas antes de o aluno utilizá-la, pois deve ser bem preparada para o melhor aproveitamento, tendo em vista que o planejamento exige dedicação e tempo. O planejamento é atividade central no exercício da docência, principalmente quando se utilizam tecnologias que apresentam inúmeros recursos e possibilidades, uma vez que a proposição de atividades colaborativas exige a definição de regras, objetos e recursos para o seu desenvolvimento.

Cabe destacar diante da temática proposta para esse trabalho de que a Internet não foi relacionada a proposição de trabalhos colaborativos e pouca ênfase foi dada as possibilidades de comunicação oferecidas por esses recursos.

$\mathrm{Na}$ situação analisada na pesquisa a Internet teve um papel fundamental, pois possibilitou a interação entre os alunos que estavam em tempos (turnos) e espaços (salas) diferenciadas, o compartilhamento do trabalho produzido e informações, a atuação sobre a versão mais atualizada do trabalho, a pesquisa sobre a temática e o registro do comportamento do grupo (interação, troca de informações, registros e acessos).

A partir da análise da atividade realizada, foi possível conhecer um pouco da perspectiva dos professores, identificando contribuições, dificuldades, modos de organização, compreensão e relação com o uso das tecnologias e com a colaboração.

\section{CONSIDERAÇÕES FINAIS}

Pode-se visualizar o computador ligado à rede como uma possibilidade de ampliar o espaço de aprender e ensinar, pois oferece suporte para a interação e comunicação, a construção coletiva, o acesso a informações e o gerenciamento de atividades a distância.

Neste trabalho, discutimos tecnologias que cada vez mais fazem parte das atividades da sociedade, fato que conduz à reflexão sobre a exclusão, mais restritamente a exclusão digital. Os indivíduos, para o exercício de sua cidadania e para ter condições de atuação social, precisam conhecer e ter familiaridade com as atuais tecnologias, o que não se restringe ao seu manuseio, mas à capacidade de utilizá-las de modo criativo, fazendo uso de seus recursos para facilitar atividades profissionais e educativas. 
No decorrer do trabalho foi possível evidenciar algumas vantagens, dificuldades e distanciamentos entre os conceitos teóricos e as práticas relativas à colaboração. As vantagens destacadas dizem respeito à possibilidade do desenvolvimento da autonomia dos alunos ao definirem sua trajetória e estratégia para o desenvolvimento da atividade. A responsabilidade decorrente dessa atitude torna o sujeito responsável pelos processos e pelos resultados da sua ação, bem como a possibilidade de interação para a construção de conhecimentos.

Por fim, enfatizamos que a formação dos professores para utilização das tecnologias na educação é fundamental para a inserção das tecnologias na escola, de modo a agregar qualidade ao ensino e contribuir com a inclusão digital dos alunos a partir da escolarização.

\section{REFERÊNCIAS}

ANDRADE, A. F.; BEILER, A. Análise de ferramentas computacionais colaborativas visando aprendizagem a distância. In: TALLER INTERNACIONAL DE SOFTWARE EDUCATIVO, 1999, Santiago [Proceedings...] Santiago, 1999.

BERBEL, N. A. N. A problematização e a aprendizagem baseada em problemas: diferentes termos ou diferentes caminhos? Interface, São Paulo, v.2, n.2, p. 139-154, 1998. Disponível em: http://www.interface.org.br/revista2/artigo3.pdf . Acesso em: 10 mar. 2004.

BRNA, P. Modelos de colaboração. Revista Brasileira de Informática na Educação. Florianópolis, n. 3, p. 9-15, setembro, 1998.

CAMPOS, F. C. A.; SANTORO, F. M.; BORGES, Marcos R. S.; SANTOS, N. Cooperação e aprendizagem on-line. Rio de Janeiro: DP\&A, 2003.

DILLENBOURG, P.; BAKER, M.; BLAYE, A.; O'MALLEY, C. The evolution of research on collaborative learning. In: SPADA, E.; REIMAN, P. Learning in humans and machine: Towards an interdisciplinary learning science. Oxford: Elsevier, 1996, p. 189-211.

FERREIRA, S. L. Um estudo sobre a interatividade nos ambientes virtuais da Internet e sua relação com a educação: o cada da Alltv. 2004. 158f. Dissertação (Mestrado em Educação) Universidade Federal de Santa Catarina, Florianópolis, 2004.

GARNIER, C.; BEDNARZ, N.; ULANOVSKAYA, I. Interações sociais e construção de um sistema de escrita dos números no ensino fundamental. In: GARNIER, C.; BEDNARZ, N. et al. Após Vygotsky e Piaget: perspectivas social e construtivista escola russa e ocidental. Porto Alegre: Ed. Artes Médicas, 1996.

GOUVEIA, L. M. B. Ambientes virtuais colaborativos: a procura de formas alternativas de interacção. Revista politécnica, Porto, n. 2, p. 1-12, dezembro, 2000. Disponível em: http://www2.ufp.pt/ lmbg/com/pdfs/rev_ispgaya20000.PDF. Acesso em: 13 de mar. 2004. 
JOLLIVET, P. NTIC e trabalho cooperativo reticular: do conhecimento socialmente incorporado à inovação sociotécnica. In: COCCO, G.; GALVÃO, A. P.; SILVA, G. (Org.). Capitalismo cognitivo: trabalho, redes e inovação. Rio de Janeiro: DP\&A, 2003.

KENSKI, V. M. Processo de interação e comunicação no ensino mediado pelas tecnologias. In: ROSA, Dalva E. G.; SOUZA, Vanilton C. de; FELDMAN, Daniel. Didáticas e práticas de ensino: interfaces com diferentes saberes e lugares formativos. Rio de Janeiro: DP\&A, 2002.

LABORDE, C. Duas utilizações complementares da dimensão social nas situações de aprendizado da Matemática. In: GARNIER, C.; BEDNARZ, N. et al. Após Vygotsky e Piaget: perspectivas social e construtivista escola russa e ocidental. Porto Alegre: Artes Médicas, 1996.

LIMA, L. O. Mutações em educação segundo McLuhan. 15 ed. Petrópolis, RJ: Vozes, 1982.

LUCENA, M. Teoria histórico-sócio-cultural de Vygotsky e sua aplicação na área de tecnologia educacional. Tecnologia Educacional. Rio de Janeiro, v. 26, p. 49-53, abr/mai/jun. ABT, 1998.

MAIA, C. (Org.). ead.br: educação a distância no Brasil na era da Internet. São Paulo: Anhembi Morumbi, 2000.

MASON, R. Models of Online Courses [online]. ALN Magazine, v. 2, n. 2, outubro, 1998. Disponível em: http://www.aln.org/alnweb/magazine/vol2_issue2/Masonfinal.htm. Acesso em: 7 jan. 2004.

PALLOFF, R. M.; PRATT, K. Construindo comunidades de aprendizagem no ciberespaço: estratégias eficientes para salas de aula on-line. Porto Alegre: Artmed, 2002.

PIVA JUNIOR., D.; AMORIN, J. A. et al. Auxiliar: uma aplicação de inteligência artificial que possibilita a potencialização da aprendizagem em Ambientes Colaborativos de Ensino. In: SIMPÓSIO BRASILEIRO DE INFORMÁTICA NA EDUCAÇÃO, 12, 2002. Porto Alegre. [Anais...] Porto Alegre: UNISINOS, 2002, p. 86-93.

ROSATELLI, M. C. et al. Ambientes de apoio à aprendizagem cooperativa. In: RAMOS, E. M. F. (Org.). Informática na Escola: um olhar multidisciplinar. Fortaleza: Editora UFC, 2003.

SANTORO, F. M.; BORGES, M. R. S.; SANTOS, N. Um modelo de cooperação para aprendizagem baseada em projetos com foco no processo cooperativo e workflow. In: SIMPÓSIO BRASILEIRO DE INFORMÁTICA NA EDUCAÇÃO, 12, 2002. Porto Alegre. [Anais...] Porto Alegre: UNISINOS, 2002, p. 358-367.

SILVEIRA, S. A. Exclusão digital: a miséria na era da informação.. São Paulo: Editora Fundação Perseu Abramo, 2001. (Coleção Brasil Urgente). 
TEIXEIRA, M. Aprendizagem baseada em problemas. Handbook, 2002. Disponível em: http://www.manuelteixeira.net/articles/documentos/texto_abp_final.pdf. Acesso em: 20 de set. 2004.

ZANELLA, A. V. Vygotsky: contexto, contribuições à psicologia e o conceito de zona de desenvolvimento proximal. Itajaí: UNIVALI, 2001.

DANIELA KARINE RAMOS

Psicóloga, Pedagoga, Mestre em Educação e Doutorando em Educação no Programa de Pós-graduação em Educação da Universidade Federal de Santa Catarina, Professora do Departamento de Psicologia e Assessora Pedagógica do Ensino Superior na Universidade Regional de Blumenau e professora do curso de Psicologia no Instituto Blumenauense de Ensino Superior (IBES). E-mail: dadaniela@gmail.com 